\title{
The relationship between superior attachment of the uncinate process of the ethmoid and varying paranasal sinus anatomy: an analysis using computerised tomography
}

\author{
Leyla Kansu, MD \\ Department of Otolaryngology-Head and Neck Surgery, Baskent University, Ankara, Turkey \\ ORCID ID: 0000-0003-1707-7760
}

\begin{abstract}
Objective: The purpose of this research was to examine how attachment of the uncinate process superiorly (SAUP) relates to possession of an agger nasi cell, pneumatisation of the middle turbinate and the measurements of the base of the skull anteriorly. The study was carried out using computerised tomography (CT).

Methods: The study involved CT imaging captured from 727 individuals with persistent sinusitis- 1454 images in total, featuring coronal section of the paranasal sinus. The frequency of SAUP, existence of an agger nasi cell, pneumatisation of the middle turbinate and how high the lamella measured laterally, were all noted. Landsberg and Friedman's classification scheme for SAUP was utilised. Statistical analysis used the chisquared test.
\end{abstract}

Results: In $1.65 \%$ of cases, SAUP was not identifiable. With regard to class of SAUP, the most frequent was type 2 , then, in descending order of frequency, types 1 , $4,3,5$ and 6 . The frequencies noted were $27.6 \%, 19.8 \%$, $15.4 \%, 14.5 \%, 12.0 \%$ and $9.0 \%$, respectively. An agger nasi cell was visualised in 894 images (61.07\%). There was pneumatisation of the middle turbinate in 395 images $(27.17 \%)$. The lamina cribrosa measured $5.58 \mathrm{~mm}$ on average.

Conclusion: There were significant correlations between the type of SAUP and the existence of agger nasi cells or of concha bullosa. However, the type of SAUP was not statistically significant in predicting the height of the lamina cribrosa.

Keywords: Paranasal sinuses, uncinate process, turbinates, skull base, multidetector computed tomography

\section{Introduction}

Sinusitis is a very frequently encountered disorder in the developed and developing world alike. For chronic cases that do not respond to pharmacological therapy, the first line therapy is endoscopic sinus surgery (ESS). The frontal sinus is one area which continues to present a significant challenge for this treatment, despite overally progress with the technique. Indeed, many practitioners do not use ESS on the frontal sinus as they are wary of an area viewed as being maze-like in its anatomical layout. ${ }^{[1]}$ Yet, exercising

too great a level of caution in dissecting the frontal recess may mean ESS achieves at best partial or no success and may even endanger the skull base, the orbit or the anterior ethmoid arterial supply. A sound knowledge of the anatomical characteristics of this area is thus a prerequisite for any surgeon contemplating the use of ESS. ${ }^{[1,2]}$

The uncinate process (UP) is the key feature of frontal anatomy needed to appreciate the layout of the frontal recess and plan successful operative interventions on the frontal sinus. ${ }^{[2]}$ The maxillary and frontal sinuses cannot be succes-
Correspondence: Leyla Kansu, MD, Department of Otolaryngology-Head and Neck Surgery Alanya Medical and Research Center, Baskent University, Alanya, Antalya, Ankara, Turkey e-mail: leylakansu@hotmail.com

Received: 07.06.2019 Accepted: 03.07.2019
Online available at: www.entupdates.org

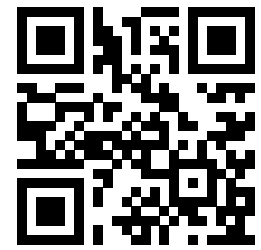


fully accessed without resecting the UP. It is very frequent for sufferers from persistent sinusitis to have an anatomically anomalous UP when the interior of the nose is investigated, it has been reported. ${ }^{[3]}$ Identifying such anomalous variations in anatomy prior to surgery is beneficial in preventing surgical mishaps involving the nasolacrimal duct, the orbit medially, the sphenopalatine artery or certain other key points. ${ }^{[4]}$

The path followed by secretions draining from the frontal sinus can be traced by first finding where the uncinate process is attached superiorly (i.e. the SAUP). Anatomical variation of the SAUP changes the size of the frontal sinus ostium as well as the dimensions of the frontal beak. ${ }^{[5]}$ If the surgeon is to achieve a sufficient exposure of the frontal sinus by opening up the frontal recess, being familiar with the anatomical variations is key. ${ }^{[6]}$ There is variation in the SAUP from person to person and thus significant. variation also exists in the way the frontal sinus is drained. ${ }^{[6,7]}$ Stammberger and Hawke were the first to identify the significance of the SAUP in this regard, which they did in a 1991 publication detailing three ways the SAUP may be attached: to the lamina papyracea, the base of the skull, or the middle concha. ${ }^{[8]}$

To be able to comprehend the frontal sinus anatomy in an individual case and deduce whether a variant of the anatomical layout is hindering sinus outflow, given the complexity of the anatomy, pre-operative imaging studies are a must. The ideal technique for imaging is computerised tomographic (CT) scanning of the paranasal sinuses (PNS), since it provides detailed anatomical views. ${ }^{[9,10]}$ Coronal views offer the best way to appreciate how SAUP relates to the frontal recess and the adjacent anatomical structures. ${ }^{[5]}$

Wormald ${ }^{[2]}$ held that the extent to which the agger nasi (AN) cell is pneumatised predicts how SAUP occurs, the frontal cell of the ethmoid playing no role in this. The greater the size of the AN cell, the further SAUP will occur in a medial direction to the base of the skull, even as far as the middle concha. ${ }^{[2]}$

Whilst there are a number of articles addressing the subject of the relationship between SAUP and an agger nasi cell, there has only been one study published in English so far that examines how different SAUP types relate to the adjacent anatomical structures. The present study utilises CT scanning to explore how SAUP type relates to existence of an AN cell, the degree to which the middle concha is pneumatised and the depth of the lamina cribrosa.

\section{Methods}

This research involved a retrospective review of CT imaging in the coronal plane of the paranasal sinuses obtained for 727 individuals in the period January 2012 to December 2016. All the individuals so scanned had persistent sinusitis that had not responded to pharmacological therapy. The imaging involved one scanner (Somatam Spirit; Siemens, Erlangen, Germany) being used without intravenous contrast agent to obtain $1 \mathrm{~mm}$ thick consecutive sections in a coronal plane. The appropriate permissions were obtained by gaining ethical approval from the Institutional Review Board (Project no: KA15/24) and ensuring written, informed consent was documented from each case

Exclusion criteria were: odontogenic sinusitis, mycetoma, extensive or repeated polyp formation, cystic fibrosis, neoplasms, nasal injury and any previous ESS. All individuals involved were at least eighteen years old.

Landsberg and Friedman have defined a classification scheme for SAUP as shown in Figure 1.a, b, c, d, e, f. This was the scheme adhered to. It works as follows: type 1: the lamina papyracea is the point of attachment, type 2: the ethmoid cell is the point of attachment, type 3: the lamina papyracea and where the middle turbinate and cribriform plate join are the points of attachment, type 4: where the middle turbinate and cribriform plate join is the point of attachment, type 5: the skull base is the point of attachment, and type 6: the middle turbinate is the point of attachment. ${ }^{[6]}$

The term CB refers to pneumatisation of the middle concha (Figure 2). The scans were examined for the existence of $\mathrm{CB}$ or AN. See figure 3. A measurement of the lateral lamellar height was performed, giving the depth of the lamina cribrosa, the measurement being chosen which was greatest amongst the various sections. The Keros scheme of classification was employed, whereby three categories exist, on the basis of the distance between the roof of the ethmoid and the cribriform plate. Keros types 1, 2 and 3 have distances of $<3 \mathrm{~mm}, 3-7 \mathrm{~mm}$ and $>7 \mathrm{~mm}$, respectively (Figure 4.a, b, c). ${ }^{[1]]}$

The observer in every case was the same person. The PACS (picture archiving and communication system) dedicated application was utilised in assessing the images morphologically. This application has built-in tools which can make the relevant measurements. The imaging for each case involved a separate evaluation of the right and left PNS region.

The SPSS software application (version 22.0; IBM Corp., Armonk, NY, USA) was used for analysis of the data. 

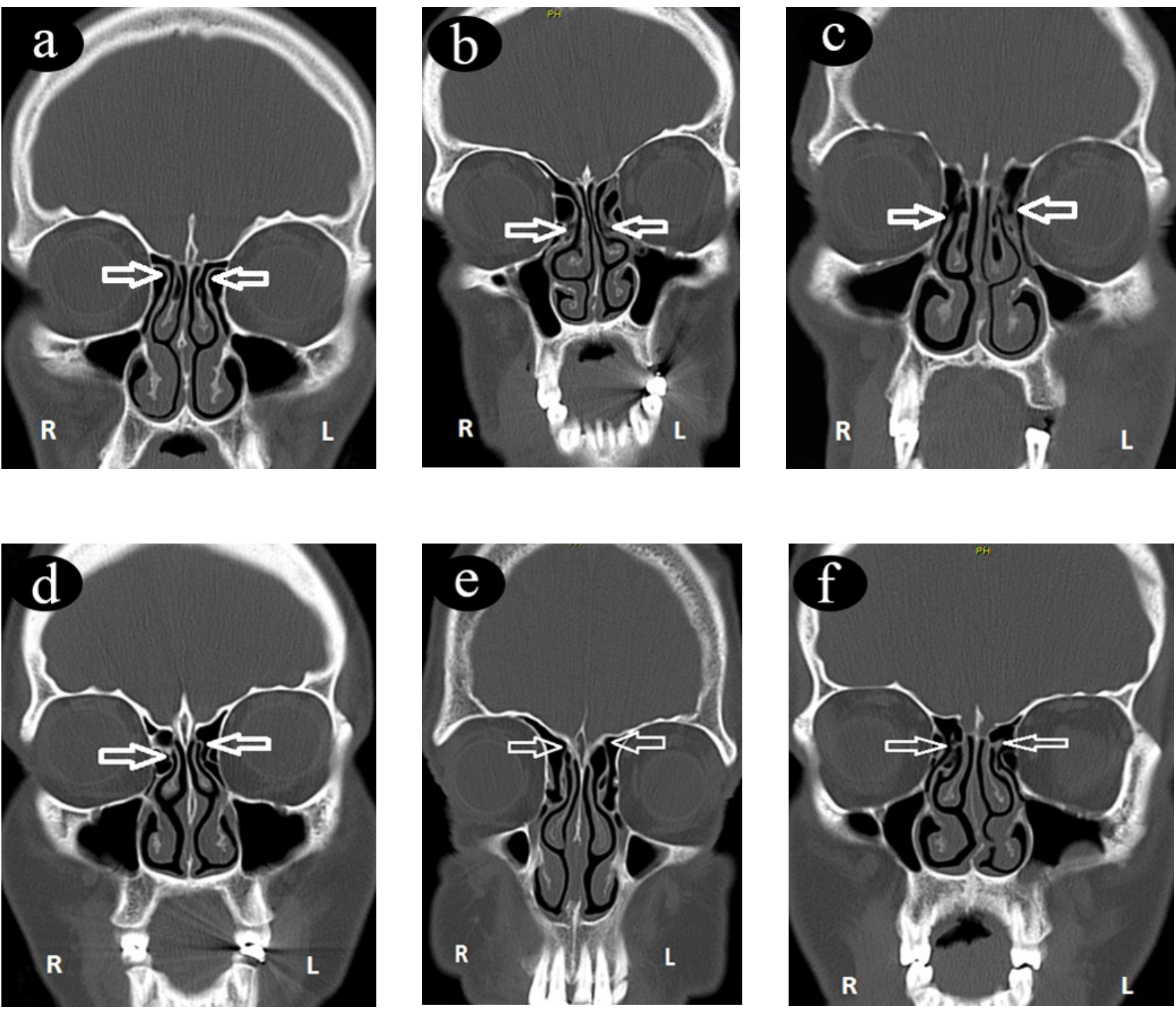

Figure 1.

The chi-squared test was used to test differences. A p value of $\leq 0.05$ was chosen as the cutoff for statistical significance.

\section{Results}

The total number of patients enrolled in this study was 727, thus 1454 sides of PNS CT images were evaluated. The study group consisted of 396 males (54.5\%) and 331 females $(45.5 \%)$. Their ages ranged from 18 to 84 years, with a mean of $37.7 \pm 14.3$ years. The main characteristics of the group are summarized in Table 1 .

\section{Uncinate process}

Six types of SAUP were identified within the PNS CT images. ${ }^{[6]}$ In 24 (1.65\%) sides, we could not identify the SAUP according to the classification described by Landsberg and Friedman. The most common type of SAUP was type 2 (400 sides, $27.6 \%$ ), followed by type 1 (288 sides, $19.8 \%$ ), type 4 (224 sides, $15.4 \%$ ), type 3 (212 sides, $14.5 \%$ ), type 5 (174 sides, $12.0 \%$ ), and type 6 (132 sides, 9.0\%). In 337 patients $(46.35 \%)$, the SAUP was the same type on both sides with the following distribution: type 1 in 74 patients 


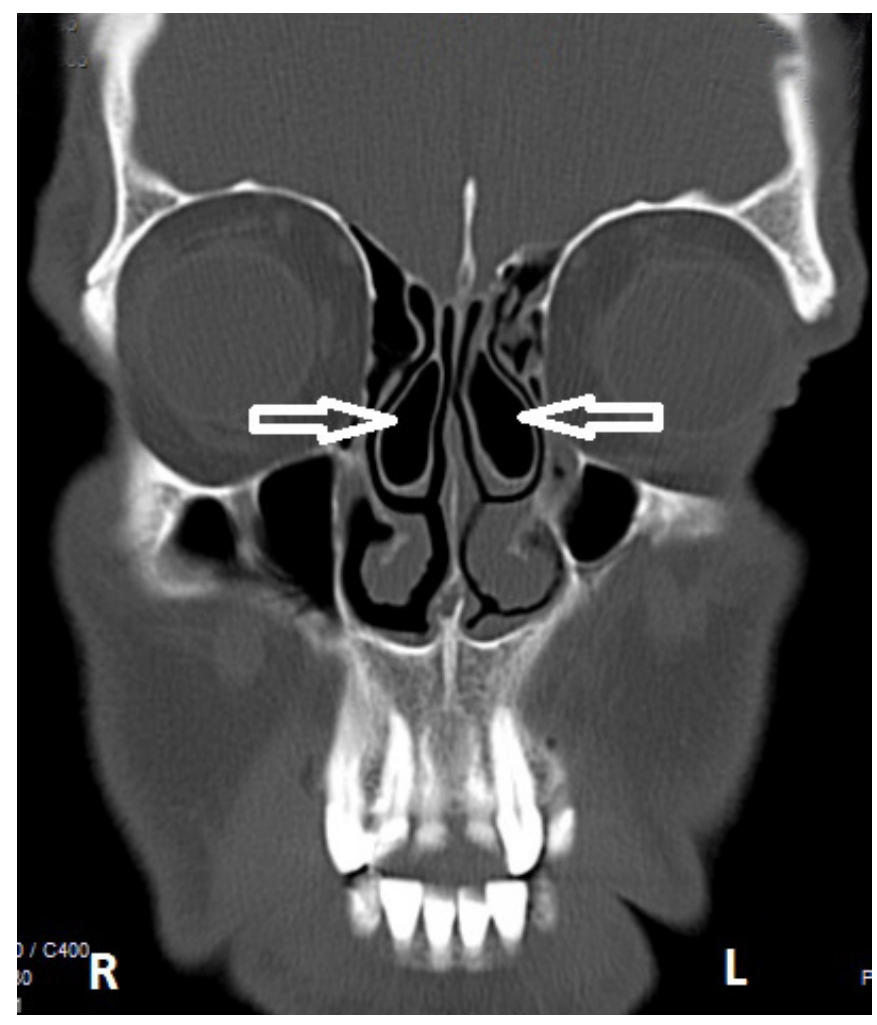

Figure 2.

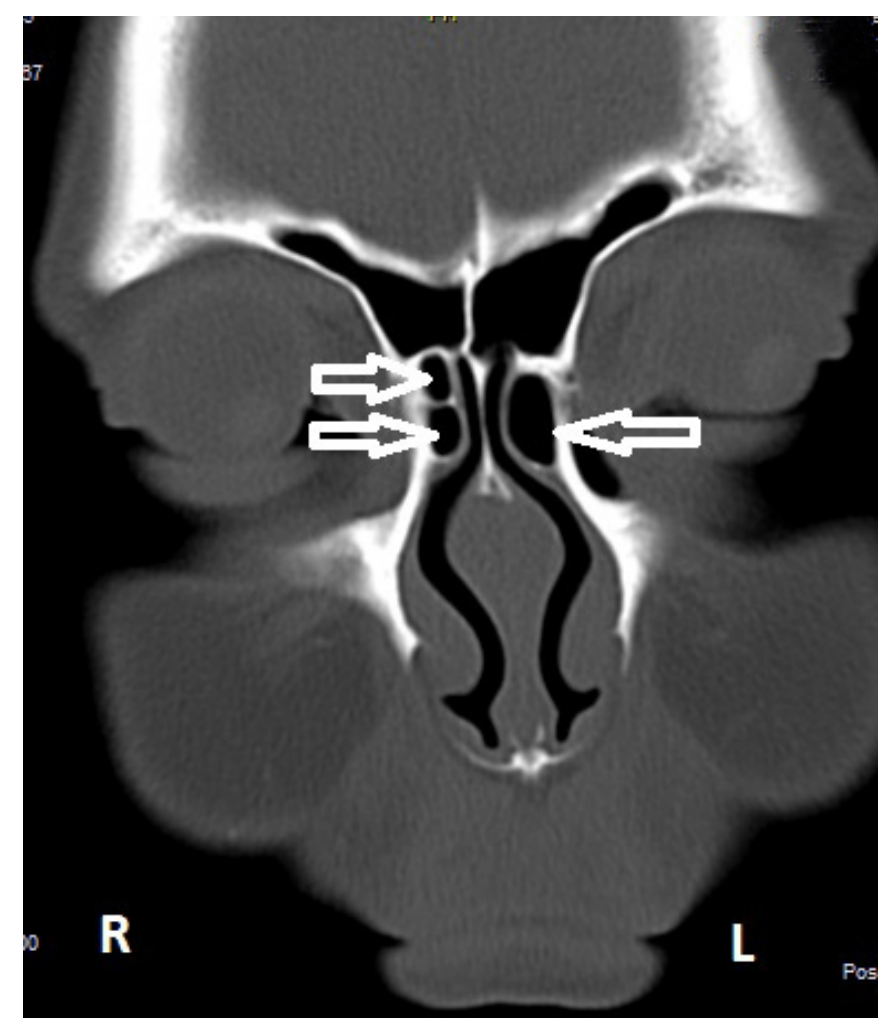

Figure 3.
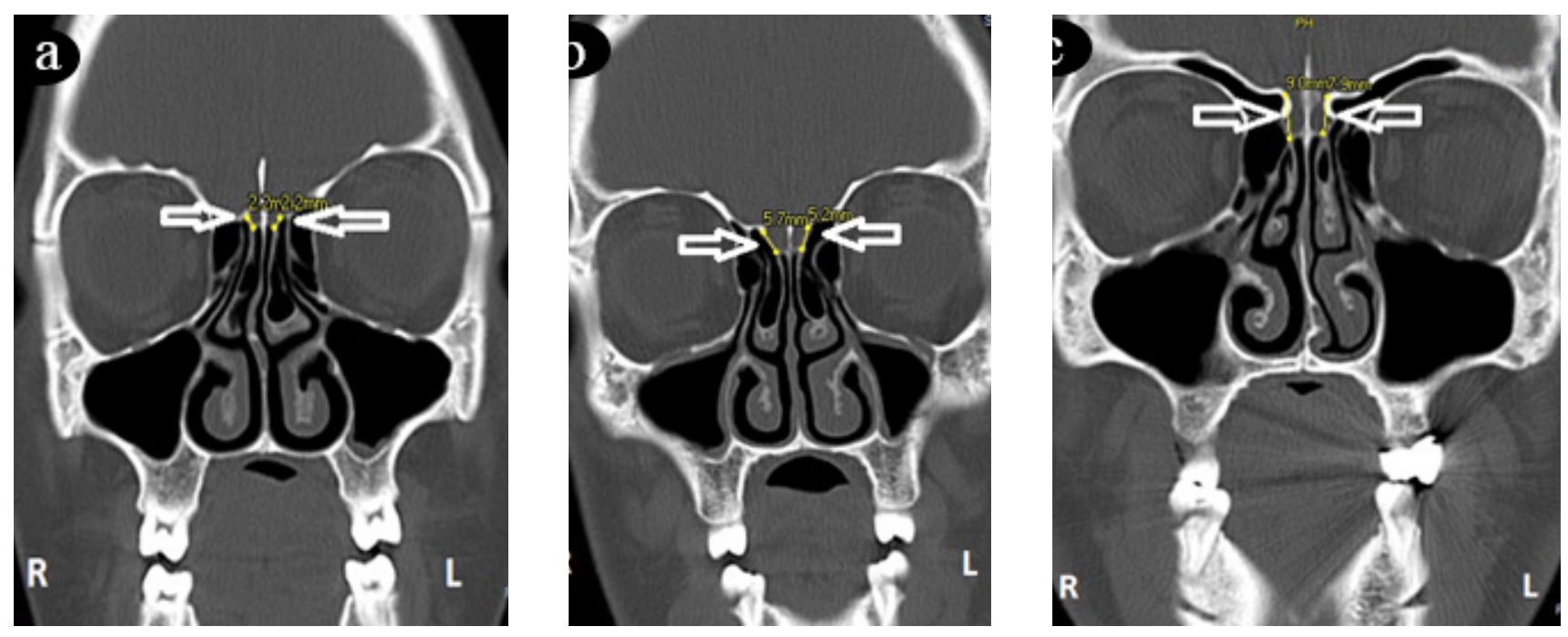

Figure 4. 


\begin{tabular}{|c|c|}
\hline \multicolumn{2}{|l|}{ Sex } \\
\hline Male & $792(54.5)$ \\
\hline Female & $662(45.5)$ \\
\hline \multicolumn{2}{|c|}{ Uncinate process attachment types } \\
\hline Type 1 & $288(19.8)$ \\
\hline Type 2 & $400(27.6)$ \\
\hline Type 3 & $212(14.5)$ \\
\hline Type 4 & $224(15.4)$ \\
\hline Type 5 & $174(12.0)$ \\
\hline Type 6 & $132(9.0)$ \\
\hline N/A & $24(1.65)$ \\
\hline \multicolumn{2}{|l|}{ Agger nasi cell } \\
\hline Present & $894(61.07)$ \\
\hline Absent & $560(38.93)$ \\
\hline \multicolumn{2}{|c|}{ Pneumatized middle turbinate } \\
\hline Present & $395(27.17)$ \\
\hline Absent & $1059(72.83)$ \\
\hline \multicolumn{2}{|l|}{ Depth of olfactory fossa } \\
\hline Keros type $1(<3 \mathrm{~mm})$ & $226(15.52)$ \\
\hline Keros type $2(3-7 \mathrm{~mm})$ & $1112(76.46)$ \\
\hline Keros type $3(>7 \mathrm{~mm})$ & $116(7.98)$ \\
\hline \multicolumn{2}{|c|}{$\begin{array}{l}\text { Data are presented as number (\%) of sides. } \\
\text { N/A, not available. }\end{array}$} \\
\hline
\end{tabular}

(21.9\%), type 2 in 109 patients (32.3\%), type 3 in 42 patients (12.4\%), type 4 in 49 patients (14.5\%), type 5 in 38 patients (11.2\%), and type 6 in 25 patients (7.4\%).

\section{Agger nasi cell}

The AN cell was present in 894 (61.07\%) of the 1454 sides. The AN cell was present bilaterally in 423 (89.8\%) patients and unilaterally in $48(10.2 \%)$ patients. The SAUP types were distributed as follows among the sides with an AN cell: type 1 in 162 sides (18.1\%), type 2 in 268 sides (29.9\%), type 3 in 140 sides (15.6\%), type 4 in 135 sides (15.0\%), type 5 in 92 sides (10.2\%), and type 6 in 88 sides (9.8\%). The relationship between the presence of the AN cell and the type of SAUP was statistically significant $(\mathrm{p}=$ 0.001) (Table 2).

\section{Concha bullosa}

Middle turbinate aeration was found in 395 of the sides (27.17\%) in our study. CB was present bilaterally in 137 patients $(53.1 \%)$ and unilaterally in 121 (46.9\%) patients. The SAUP types were distributed as follows among the sides with CB: type 1 in 57 (14.1\%) sides, type 2 in 76 (19.1\%), type 3 in 84 (21.2\%), type 4 in 53 (13.4\%), type 5 in $53(13.4 \%)$, and type 6 in $69(17.5 \%)$. There was a statis-

Table 2. Types of superior attachment of the uncinate process

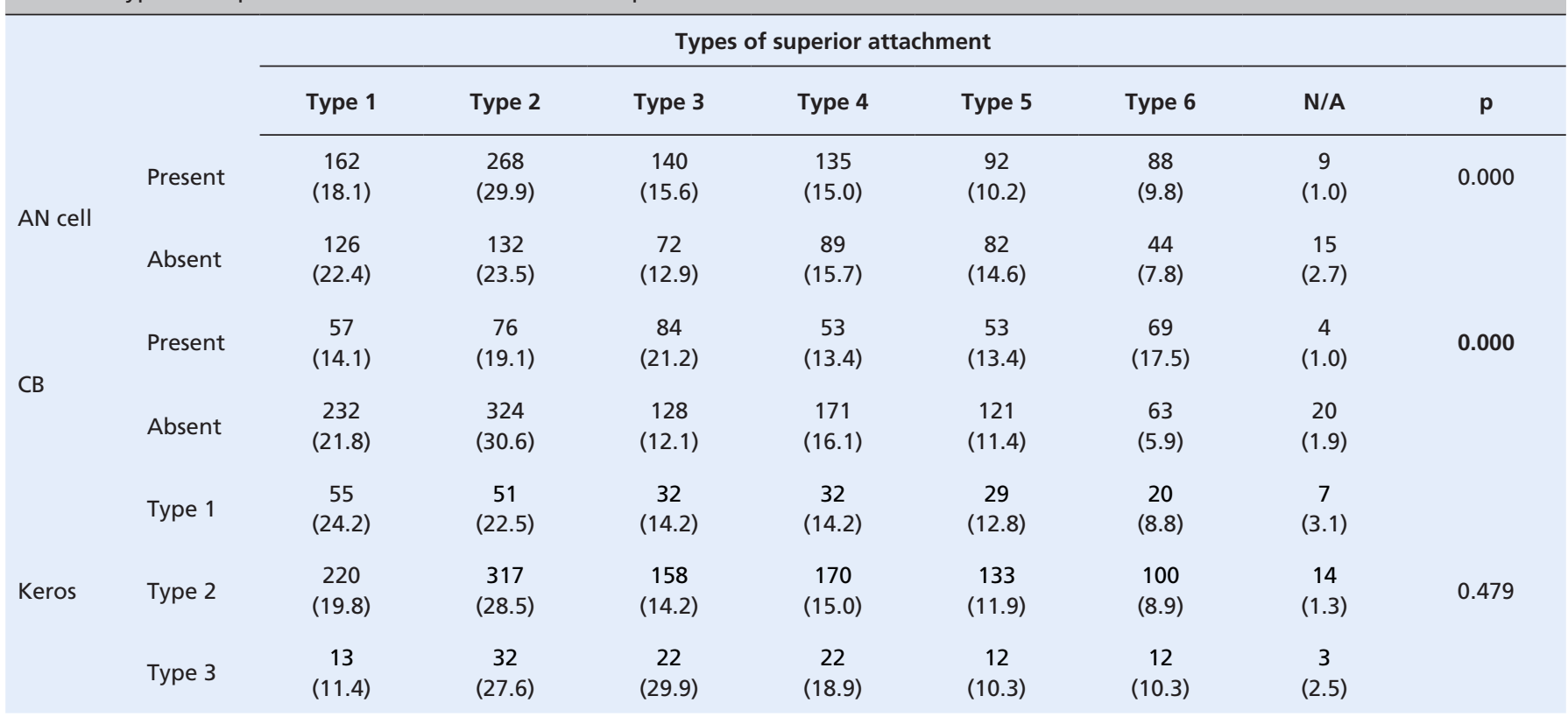

Data are presented as number (\%) of sides.

$A N$, agger nasi; $C B$, concha bullosa 
tically significant association between the presence of $\mathrm{CB}$ and the SAUP type $(\mathrm{p}=0.00)$ (Table 2). The frequency of type 6 (attachment of SAUP to the middle turbinate) was significantly higher in the presence than in the absence of CB (17.5\% vs. $5.9 \%$, respectively).

\section{Depth of lamina cribrosa}

The mean depth of the lamina cribrosa was $5.58 \pm 1.60$ $\mathrm{mm}$ amongst all patients $(5.42 \pm 1.55 \mathrm{~mm}$ in women, 5.72 $\pm 1.67 \mathrm{~mm}$ in men). The depth of the olfactory fossa was $<3 \mathrm{~mm}$ (Keros type 1 ) in $226(15.5 \%)$ sides, 3 to $7 \mathrm{~mm}$ (Keros type 2) in 1112 (76.4\%) sides, and $>7 \mathrm{~mm}$ (Keros type 3 ) in $116(7.9 \%)$ sides (Table 1). No statistically significant asymmetry was present between the two sides when the difference in the depth of the lamina cribrosa in the same patient was compared. The relationship between the depth of the lamina cribrosa and the SAUP type was not statistically significant $(\mathrm{p}=0.47)$ (Table 2$)$.

\section{Discussion}

During embryological development, the UP has its origin medially in the lateral cartilaginous capsule. It first appears at 10 weeks gestation. Before the 12th week of gestation, the UP and infundibulum already exist in simple form. The sinuses (maxillary and ethmoid) form in conjunction with these structures. ${ }^{[12]}$

It is unknown what the purpose of the UP is. Possibly, it may be a vestige of embryological development. ${ }^{[13]}$ Nonetheless, current research has highlighted its significant part in the way the nose and sinuses function in respiration. It functions as a physical barrier to entry for bacteria and aeroallergens into the sinuses and the airflow is probably directed away from the sinuses by the same mechanism. ${ }^{[13]}$

There are three portions of the UP from an anatomical perspective: the horizontal, middle and superior portions. These attach to the ethmoidal process of the lower concha and the palatine bone, the lacrimal bone and lamina papyracea, and to different degrees into the frontal recess, respectively. ${ }^{[14,15]}$ Wormald's view was that the UP has potential insertion on its superior attachment to the lamina papyracea, base of the skull or middle concha. It may also insert at several points. ${ }^{[2]}$

When planning for surgery, the position of the UP is a key issue. There are two separate scenarios to be borne in mind. Either the UP has an attachment to the nasal wall in a lateral direction, the lamina papyracea or the agger nasi cell, in which case the frontal recess is bounded by the UP and bulla lamella; or the UP has its superior attachment to the front of the base of the skull or to the middle concha, in which case the frontal recess will be inaccessible. In the latter scenario, it is imperative to perform uncinectomy using minimum pressure, otherwise cerebrospinal fluid may leak from the nose afterwards or there may be injury to the anterior cranial fossa or the orbit and structures within. ${ }^{[5]}$

Thus, the SAUP, within the nasofrontal recess, is an important determinant of how the frontal sinus drains and operations involving the frontal sinus involve considering its position carefully first. ${ }^{[3,5]}$ If the attachment of the UP is to the lamina papyracea on the superior or lateral aspect, the UP will constitute the lateral boundary of the frontal recess. On the other hand, insertion of the UP into the basal skull or the middle concha leads to the UP constituting the frontal recess boundary medially. In the latter case, the frontal sinus will drain straight into the ethmoid infundibulum in an anterior direction to the middle meatus. ${ }^{[16,17]}$

Research looking into how the uncinate process inserts superiorly has produced varying conclusions. Landsberg and Friedman found that the SAUP could occur in the following ways: to the lamina papyracea; to the posteromedial aspect of the agger nasi cell; to the lamina papyracea and the area where the middle concha joins the cribriform plate; to the area where the middle concha and cribriform plate join; to the roof of the ethmoid; and to the middle concha. These various attachment patterns occurred in $52.0 \%, 18.5 \%$, $17.5 \%, 7 \%, 3.6 \%$ and $1.4 \%$,respectively. ${ }^{[6]}$ The research presented here uses the same criteria as Landsberg and Friedman, but discovered frequencies of $19.8 \%, 27.6 \%$, $14.5 \%, 15.4 \%, 12 \%$ and $9 \%$, for the various attachment points considered in the same order as listed for Landsberg and Friedman's study. Thus, it was more common for the SAUP to be to the cribriform plate and middle concha than Landsberg and Freidman had concluded. ${ }^{[6]}$

Güldner et al reviewed CT imaging from 865 cases, observing that SAUP occurred to the lamina papyracea in $64.3 \%$, to the basal skull in $25.5 \%$, and to the middle concha in $10.2 \% \cdot{ }^{[10]}$ Srivastava and Sushant discovered that attachment of the UP to the lamina papyracea, the basal skull and the middle concha occurred with frequencies of $57.8 \%, 20.3 \%$ and $6.2 \%$, respectively. ${ }^{[7]}$ Ercan et al concluded that the majority of individuals have SAUP to the lamina papyracea $(62.6 \%)$, whilst attachment to the basal skull was the third most frequent occurrence, in $14.4 \%$ of cases. ${ }^{[18]}$ Tuli et al report that the uncinate process attached 
most commonly to the lamina papyracea ( $79.8 \%$ of cases), whereas the most infrequent type attached to the basal skull. ${ }^{[4]}$ Liu et al state that the frequency of attachment to the lamina papyracea was $70.4 \%$, the middle concha was $10.2 \%$ and the basal skull $6.1 \% .{ }^{[17]}$ Thus, in every study, ours included, SAUP is most frequently found to occur as insertion in the lamina papyracea.

Ercan et al. reported that $65 \%$ of individuals had SAUP that was identical on both sides, the remaining $35 \%$ being different. ${ }^{[18]}$ Liu et al noted SAUP to be the same on both sides in $61 \%$ of individuals. ${ }^{[17]}$ The present study put the figure at $46.3 \%$ of cases.

The agger nasi cell is the air cell within the ethmoid bone found furthest forward. It is anterolateral and below the frontal recess. If an AN cell exists, CT imaging usually reveals its position as forward of the middle concha. ${ }^{[2]}$ Looking intranasally, the lateral wall of the nose may have a slight bulge slightly forward of where the middle concha inserts that shows the position of the AN cell. ${ }^{[14]}$ This structure has an important role to play in allowing identification of the access to the frontal recess at operation. ${ }^{[2]}$

A number of researchers have quoted disparate estimates of the frequency with which AN cells occur. Messerklinger ${ }^{[19]}$, working from cadaveric anatomy, put the frequency at between 10 and $15 \%$. Badia et al were interested in how ethnic origin influences the anatomy of the sinuses and nasal cavity. They employed CT imaging of the paranasal sinuses and concluded that the most common differences were in the possession of an AN cell. ${ }^{[9]}$ Kantarci et al, Fadda et al, Krezski et al and Bolger et al all quote figures for the prevalence of an AN cell, coming up with $47.0 \%$, $24.3 \%, 52.9 \%$ and $98.5 \%$, respectively. ${ }^{[20-23]}$ In our case, we estimated the prevalence as $61.07 \%$. Landsberg and Friedman, Liu et al, Ercan et al, Cheng et al, Zhang et al and Wormald all quote higher prevalences: $78.0 \%, 81.8 \%$, $83.3 \%, 88.9 \%, 90.0 \%$ and $98.5 \%$, respectively ${ }^{[2,6,16-18,24]}$.

Landsberg and Friedman discovered that AN cells were present on CT imaging on both the left and right in $94.0 \%$ of cases, the remaining $6.0 \%$ being unilateral. ${ }^{[6]}$ The corresponding figures from the study of Liu et al. were $78.0 \%$ and $7.6 \%{ }^{[17]}$, and from Ercan et al's study, $82.6 \%$ and $17.4 \% .{ }^{[18]}$ Our figures for bilaterality vs unilaterality were $89.8 \%$ vs $10.2 \%$.

In embryological development, the uncinate process and the agger nasi cell share an origin in the first ethmoturbinal. The uncinate process is formed from the descending portion of the first ethmoturbinal, the ascending portion of which undergoes regression, forming an AN cell in the process. The medial, inferior and superior anatomical relations of the AN cell consist of portions of the UP ${ }^{[17]}$, a situation which Zhang et al were able to demonstrate through both spiral cranial CT and conventional dissections of cadaveric specimens. ${ }^{[24]} \mathrm{A}$ full appreciation of the anatomical format of the frontal recess depends upon grasping how the UP and AN cell are related ${ }^{[18]}$ If an AN cell is highly pneumatised, there is a corresponding increase in size, leading to the middle concha being attached more superomedially, and consequently the frontal recess becomes narrowed. If the frontal sinus cannot drain properly as a result, sinusitis may ensue. ${ }^{[17,20]}$

How the existence of an AN cell and the attachment of the UP occurs superiorly has been examined by both Liu et $a l$ and Ercan et al, but neither research team discovered relationships that were not certainly chance findings. ${ }^{[17,18]}$ Cheng et al reached somewhat similar conclusions, with no clear correlation between the existence of an AN cell and the way the UP attached superiorly. ${ }^{[16]}$ Our study did, however, find just such a correlation: there was a statistically significant correlation between the attachment type of SAUP and the existence of an AN cell, when the sides with or without an AN cell were compared (29.9\% vs $23.5 \%$ ).

$\mathrm{CB}$ as a term dates from 1862, when it was first used with reference to pneumatisation of the middle concha. At that time, cadaveric dissection techniques put the incidence at between 9 and 20\%. ${ }^{[21]}$ The key consequence of this anatomical anomaly within the middle turbinate is that it may lead to the turbinate becoming deformed and thus provoke recurrent ethmoid sinusitis through preventing proper drainage of the area.

Cheng et al. reported that CB was present in $30.9 \%$ of cases, whilst Krzeski et al put the figure at $37.5 \%$. The corresponding value in Ozcan et al was 48.1\% ${ }^{[16,22,25]}$. Fadda et al used CT imaging of the paranasal sinuses from 200 individuals to show a prevalence of CB of $49.5 \%$ (69 cases). ${ }^{[21]}$ Badia et al found $\mathrm{CB}$ to be the second most frequent type of paranasal inusal anatomy seen on CT. ${ }^{[9]}$ Gun et al found that $41.0 \%$ of cases had pneumatisation within the middle concha on the right and $39.1 \%$ on the left. ${ }^{[2]}$ In our research, CB was found in $27.17 \%$ of cases, of which $53.1 \%$ were bilateral and $46.9 \%$ unilateral.

In our study, if $\mathrm{CB}$ were present, this conferred a greater probability (17.5\%) that the UP would be inserted superiorly in the middle concha than when $\mathrm{CB}$ was absent 
(5.9\%). Cheng et al reported comparable findings. ${ }^{[16]}$ These findings can be interpreted as showing that pneumatisation of the middle concha pushes the UP closer towards it and thus increases the chance that attachment will occur at that point.

Operating on the paranasal sinuses involves the risk of injury to the roof of the ethmoid. The medial portion consists of the cribriform plate, whilst the lateral lamella forms the lateral border of the olfactory fossa. The lateral lamella is a continuation of the middle concha. Here the ethmoid is at its narrowest. There may be extensive variation in the height of both the roof of the ethmoid and the cribriform plate. Keros ${ }^{[1]}$ outlined three variants in his 1965 paper, which addressed how the depth of the olfactory fossa relates to the roof formed by the ethmoid by studying 450 cadaveric skulls. The incidence of type 1, 2 and 3 ethmoid roof types were $12 \%, 70 \%$ and $18 \%$, respectively.$^{[11]}$

Different ethnic groups are associated with differences in the depth of the olfactory fossa. Şahin et al. found the average depth to be $6.0 \mathrm{~mm}$ on the left, whilst the right had a depth of $6.2 \mathrm{~mm} .{ }^{[27]}$ The depth of the cribriform plate in Italian individuals was $5.9 \mathrm{~mm}$ on average, whilst for Turkish individuals the depth was $6.1 \mathrm{~mm} .{ }^{[27]}$ In our study, the lamina cribrosa had an average depth of $5.58 \mathrm{~mm}$.

Gauba et al. ascertained the prevalence of Keros types 1,2 and 3 as $34 \%, 28 \%$ and $38 \%$, respectively. ${ }^{[28]}$ Adeel et $a l$, however, give the corresponding values as $29.8 \%, 48.7 \%$ and $21.4 \%{ }^{[29]}$ The lamina cribrosa had an average depth of $5.35 \mathrm{~mm}$ in their study. Fadda et al found the prevalence of Keros types 1, 2 and 3 to be $15.7 \%, 7.8 \%$ and $1.4 \%$, respectively ${ }^{[21]}$, whereas Güldner et al. report the correspon- ding values as $17.3 \%, 58.6 \%$ and $24.1 \%{ }^{[10]}$ and Şahin et al as $10 \%, 61 \%$ and $29 \% .{ }^{[27]}$ Cheng et al report that $37.8 \%$ of their series had an olfactory fossa with a depth less than $3 \mathrm{~mm}, 52.3 \%$ had an olfactory fossa with a depth between 3 and $7 \mathrm{~mm}$, and $9.9 \%$ of cases had an olfactory fossa with a depth exceeding $7 \mathrm{~mm} .{ }^{[16]}$ Our research produced values for Keros types 1 to 3 of $15.5 \%, 76.4 \%$ and $7.9 \%$, respectively.

Our research examined how the type of SAUP relates to the height of the cribriform plate of the ethmoid. We found that the type of SAUP and the depth of olfactory fossa were not correlated at the level of statistical significance. Thus, our findings confirm what Cheng et al have already written. ${ }^{[16]}$

\section{Conclusion}

To appreciate fully the anatomical basis of sinus drainage via the frontal recess, it is vital to know how the superior part of the uncinate process relates to the adjacent anatomical structures. This research looked for correlations amongst the format of the upper UP, the existence of an AN cell, $\mathrm{CN}$ and the height of the lamina cribrosa. The type of SAUP and the presence or absence of both an AN cell or $\mathrm{CB}$ are significantly correlated, but the type of SAUP and the height of the lamina cribrosa are not.

Acknowledgement: The author wishes to thank Dr. Nalan Akalin for her help with the statistical analysis.

Conflict of Interest: No conflicts declared. 


\section{References}

1. Başak S, Akdilli A, Karaman CZ, Kunt T. Assessment of some important anatomical variations and dangerous areas of the paranasal sinuses by computed tomography in children. Int J Pediatr Otorhinolaryngol 2000;55:81-9.

2. Wormald PJ. The agger nasi cell: the key to understanding the anatomy of the frontal recess. Otolaryngol Head Neck Surg 2003;129:497-507.

3. Netto B, Piltcher OB, Meotti CD, Lemieszek J, Isolan GR. Computed tomography imaging study of the superior attachment of the uncinate process. Rhinology 2015;53:187-91.

4. Tuli IP, Sengupta S, Munjal S, Kesari SP, Chakraborty S. Anatomical variations of uncinate process observed in chronic sinusitis. Indian $\mathrm{J}$ Otolaryngol Head Neck Surg 2013;65:157-61.

5. Mahmutoğlu AS, Çelebi I, Akdana B, et al. Computed tomographic analysis of frontal sinus drainage pathway variations and frontal rhinosinusitis. J Craniofac Surg 2015;26:87-90.

6. Landsberg R, Friedman M. A computer assisted anatomical study of the nasofrontal region. Laryngoscope 2001;111:2125-30.

7. Srivastava M, Sushant T. Role of anatomic variations of uncinate process in frontal sinusitis. Indian J Otolaryngol Head Neck Surg 2016;68:441-4.

8. Stammberger H, Hawke M. Functional endoscopic sinus surgery: the Messerklinger technique. Decker, Philadelphia, 1999 pp 61-90.

9. Badia L, Lund VJ, Wei W, Ho WK. Ethnic variation in sinonasal anatomy on CT-scanning. Rhinology 2005;43:210-4.

10. Güldner C, Zimmermann AP, Diogo I, Werner JA, Teymoortash A. Age dependent difference of the anterior skull base Int J Pediatr Otorhinolaryngol 2012;76:822-8.

11. Keros P. Uber die praktische bedeutung der niveauunterschiede der lamina cribrosa des etmoids. [Article in Germany] Z Lar Rhin Otol 1965;41:808-10.

12. Bingham B, Wang RG, Hawke M, Kwok P. The embryonic development of the lateral nasal wall from 8 to 24 weeks. Laryngoscope 1991;101:992-7.

13. Nayak DR, Balakrishnan R, Murty KD. Functional anatomy of the uncinate process and its role in endoscopic sinus surgery. Indian J Otolaryngol Head Neck Surg 2001;53:27-31.

14. Lund VJ, Stammberger H, Fokkens WJ, et al. European position paper on the anatomical terminology of the internal nose and paranasal sinuses. Rhinol Suppl 2014;24:1-34.

15. Wake M, Takeno S, Hawke M. The uncinate process: a histological and morphological study. Laryngoscope 1994;104:364-9.

16. Cheng SY, Yang CJ, Lee $\mathrm{CH}$, et al. The association of superior attachment of uncinate process with pneumatization of middle turbinate: a computed tomographic analysis. Eur Arch Otorhinolaryngol 2017;274:1905-10.
17. Liu SC, Wang CH, Wang HW. Prevalence of the uncinate process, agger nasi cell and relationship in a Taiwanese population. Rhinology 2010;48:239-44.

18. Ercan I, Cakır BO, Sayın I, Başak M, Turgut S. Relationship between the superior attachments type of uncinate process and presence of agger nasi cell: a computer-assisted anatomic study. Otolaryngol Head Neck Surg 2006;134:1010-4.

19. Messerklinger W. On the drainage of the normal frontal sinus of man. Acta Otolaryngol (Stockh) 1967; 63:176-81.

20. Kantarci M, Karasen RM, Alper F, Onbas O, Okur A, Karaman A. Remarkable anatomic variations in paranasal sinus region and their clinical importance. Eur J Radiol 2004;50:296-302.

21. Fadda GL, Rosso S, Aversa S, Petrelli A, Ondolo C, Succo G. Multiparametric statistical correlations between paranasal sinus anatomic variations and chronic rhinosinusitis. Acta Otorhinolaryngol Ital 2012;32:244-51.

22. Krzeski A, Tomaszewska E, Jakubczyk I, Galewicz-Zielinska A. Anatomic variations of the lateral nasal wall in the computed tomography scans of patients with chronic rhinosinusitis. Am J Rhinol 2001;15:371-5.

23. Bolger WE, Butzin CA, Parsons DS. Paranasal sinus bony anatomic variation and mucosal abnormalities: $\mathrm{CT}$ analysis for endoscopic sinus surgery. Laryngoscope 1991;101:56-64.

24. Zhang L, Han D, Ge W, et al. Anatomical and computed tomographic analysis of the interaction between the uncinate process and the agger nasi cell. Acta Otolaryngol 2006;126:845-52.

25. Ozcan KM, Selcuk A, Ozcan I, Akdogan O, Dere H. Anatomical variations of nasal turbinates. J Craniofac Surg 2008;19:1678-82.

26. Gun R, Yorgancilar E, Bakir S, et al. The relationship between pneumatized middle turbinate and the anterior ethmoid roof dimensions: a radiologic study. Eur Arch Otorhinolaryngol 2013;270:1365-71.

27. Şahin C, Yılmaz YF, Titiz A, Ozcan M, Ozlügedik S, Unal A. Analysis of Ethmoid Roof and Cranial Base in Turkish Population. [Article in Turkish] KBB ve BBC Derg 2007;15:1-6.

28. Gauba V, Saleh GM, Dua G, Agarwal S, Ell S, Vize C. Radiological classification of anterior skull base anatomy prior to performing medial orbital wall decompression. Orbit 2006;25:93-6.

29. Adeel M, Ikram M, Rajput MS, Arain A, Khattak YJ. Asymmetry of lateral lamella of the cribriform plate: a software-based analysis of coronal computed tomography and its clinical relevance in endoscopic sinus surgery. Surg Radiol Anat 201335:843-7.

This is an open access article distributed under the terms of the Creative Commons Attribution-NonCommercial-NoDerivs 3.0 Unported (CC BY- NC-ND3.0) Licence (http://creativecommons.org/licenses/by-nc-nd/3.0/) which permits unrestricted noncommercial use, distribution, and reproduc- tion in any medium, provided the original work is properly cited.

Please cite this article as: Kansu L. The relationship between superior attachment of the uncinate process of the ethmoid and varying paranasal sinus anatomy an analysis using computerised tomography. ENT Updates 2019;9(2): 81-89 